\title{
О СОСТАВАХ ХРОМИСТЫХ ПИРОПОВ ЛЕРЦОЛИТОВЫХ ПАРАГЕНЕЗИСОВ ИЗ НЕАЛМАЗОНОСНЫХ И АЛМАЗОНОСНЫХ КИМБЕРЛИТОВ
}

\author{
А. С. Иванов ${ }^{1}$, 3. В. Специус ${ }^{1}$, И. В. Ащепков ${ }^{2}$, А. В. Толстов ${ }^{1}$ \\ ${ }^{1}$ НИГП АК «АЛРОСА» ПАО, г. Мирный \\ ${ }^{2}$ ГИИ СО РАН им. В.С. Соболева, г. Новосибирск
}

Поступила в редакцию 17 июля 2019 г.

\begin{abstract}
Аннотация: пироп относится $\kappa$ числу ведущих индикаторных минералов большинства мантийных парагенезисов в кимберлитах. Кроме того, несомненно, он наиболее информативен и наиболее изучен как представитель минералов мантийных пород перидотитового и эклогитового состава. Классической остается на сегодняшний день классификация составов пиропов, которая основана на диаграмме Н. В. Соболева $\mathrm{CaO}-\mathrm{Cr}_{2} \mathrm{O}_{3}$ [1]. Дискретные поля на диаграмме позволяют отнести состав пиропа $\kappa$ конкретным парагенезисам. В данной работе показано, что редкоземельнье элементы неравномерно накапливаются в составах пиропов из алмазоносного кимберлита трубка Сюльдюкарская и неалмазоносного кимберлита трубки Шандонгу [2]. Пузырьковые диаграммы дополняют информаџией популярную диаграмму. При этом у графика появляется новая информация, которая показывает критерии различия по этим признакам составов пиропов из алмазоносных и неалмазоносных кимберлитов. В работе определень дополнительные характерные особенности для составов пиропов лериолитовых парагенезисов из алмазоносных кимберлитов и неалмазоносных кимберлитов по содержаниям марганиа и магния. Для алмазоносных кимберлитов характерны составы пиропов лерцолитовых парагенезисов с повышенными значениями окиси марганща более 0,4\% весовых и пониженными значениями окиси магния менее $20 \%$ весовых.
\end{abstract}

Ключевые слова: пироп, алмазоносный кимберлит, рекоземельные элементы, пузырьковые диаграммь

\section{THE COMPOSITION OF CHROMOUS PYROPES LHERZOLITIC PARAGENESIS FROM DIAMONDIFEROUS KIMBERLITES AND PALMISANOS}

\begin{abstract}
: pyropes are among the leading typomorphic minerals of the majority of mantle parageneses in kimberlites. In addition, it is undoubtedly the most informative and most studied as a representative of minerals of mantle origin of peridotite paragenesis and eclogite. It is remains classic to date the classification of the compositions of pyropes, which is based on the chart $\mathrm{N}$. V. Sobolev $\mathrm{CaO}-\mathrm{Cr}_{2} \mathrm{O}_{3}$ [1]. The discrete fields on the diagram allow us to refer the composition of pyrope to the definite parageneses. In this work it is shown that rare-earth elements are unevenly accumulated in the pyropes of diamondiferous kimberlite Seldyukarskaya pipe and barren kimberlite pipe Shandongu [2]. The bubble chart is complemented by information popular chart additional features. At the same time, additional information appears in the graph, which shows the criteria for the difference in these characteristics of the compositions of pyropes from diamondiferous and non-diamondiferous kimberlites. The study also identified additional characteristics to compositions of lherzolitic paragenesis pyropes from diamondiferous kimberlites and barren kimberlites contents of manganese and magnesium. For diamondiferous kimberlites typical of the compositions of pyropes of lerzolitic parageneses with high values of manganese oxide more than $0.4 \mathrm{wt} \%$ and with low values of magnesium oxide less than $20 \mathrm{wt} \%$. Keywords: pyrope, diamond-bearing kimberlite, rare earth elements, bubble diagrams
\end{abstract}

\section{Введение}

Цель данной работы заключалась в определении химических различий в составах пиропов лерцолитовых парагенезисов из алмазоносных и неалмазонос- ных кимберлитов. Авторы рекомендуют комплексно изучать пиропы с учетом всех измеренных элементов, входящих в их состав. Область составов пиропов из лерцолитовых парагенезисов довольно широкая по 
своей природе. Составы пиропов из алмазоносных и неалмазоносных лерцолитовых парагенезисов хорошо различаются по содержанию окиси марганца и магния. На примере близких содержаний представительных выборок осуществлено сравнение составов пиропов из алмазоносного кимберлитового тела (трубка Сюльдюкарская, Якутия) и не алмазоносного кимберлита (трубка Шандонгу, Ангола) [2].

\section{Методика эксперимента}

На хорошо известной диаграмме Н. В. Соболева [1] пиропы этих двух выборок демонстрируют явно близкий состав. Составы большей части зерен (более 70 \%) пиропов относятся к лерцолитовым парагенезисам по содержанию окиси хрома и кальция и очень близки по характеру основного тренда (рис. 1).

Составы пиропов эклогитовых парагенезисов трубки Сюльдюкарская (рис. 1) менее кальциевые и более железистые, чем составы пиропов трубки Шандонгу. Наиболее характерные отличительные особенности составов пиропов из этих двух кимберлитовых тел продемонстрированы и хорошо выражены на диаграммах $\mathrm{MgO}-\mathrm{MnO}$ (рис. 2).
Составы пиропов трубки Шандонгу характеризуются повышенными значениями окиси магния на уровне 21 мас. \% и их пироповый минал выше, а содержания окиси марганца находятся в среднем на уровне значений 0,4 мас. \% (рис. 2). Нами изучены составы минералов трех ксенолитов из кимберлита трубки Шандогу (рис. 3).

Все они представлены обломками биминеральных эклогитов размером 3-5 мм, с содержанием граната около 60 \%. Ксенолиты представлены сростками светлозеленых зерен клинопироксенов, образующих основную ткань породы, с коричневато-оранжевыми зернами гранатов неправильной и овальной формы, размером 0,5-2,0 мм. По содержанию основных породообразующих элементов в гранатах их можно отнести к магнезиальным эклогитам (табл. 1). Следует отметить относительно высокое содержание хрома (до 0,9 мас. \%), а также повышенное содержание марганца ( $>0,2$ мас. \% MnO) в пиропах всех образцов (табл. 1). Низкое содержание или полное отсутствие окиси натрия в проанализированных зернах пиропов свидетельствует о том, что они не соответствуют гранатам алмазосодержащих эклогитов или пиропам из сростков с алмазами.
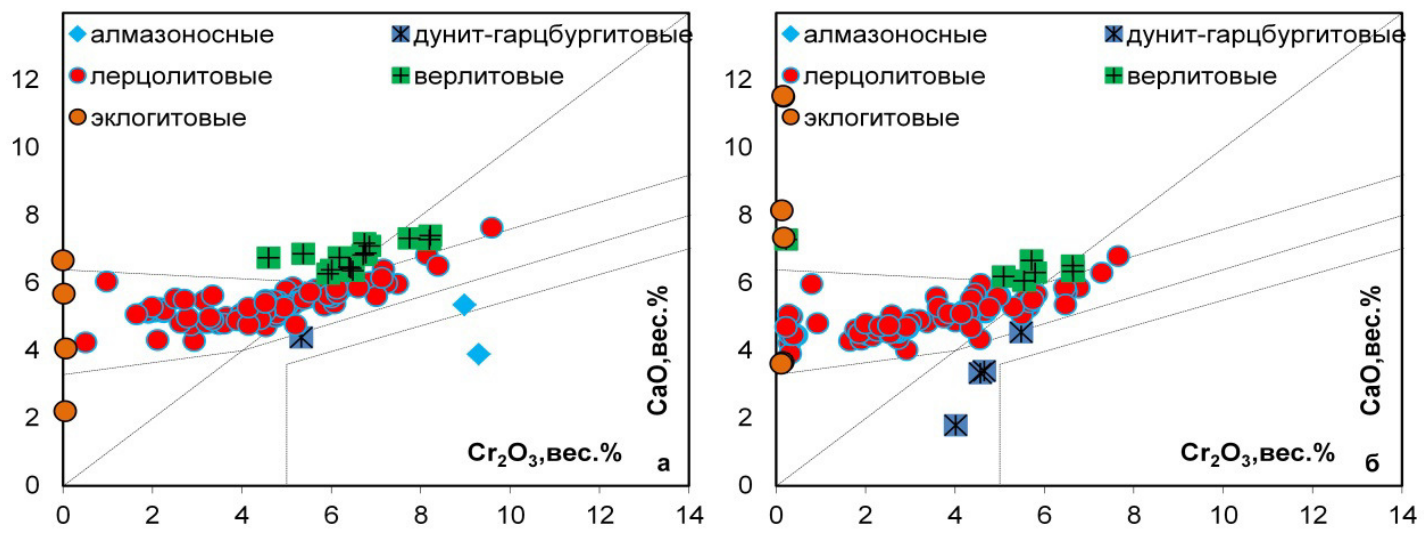

Puc. 1. Диаграммы Н.В. Соболева для составов пиропов алмазоносного кимберлита трубка Сюльдюкарская (Якутия) (а) и неалмазоносного трубка Шандонгу (Ангола) (б). На диаграммах различными значками показаны составы пиропов разных парагенетических групп по классификации Н. В. Соболева [1].
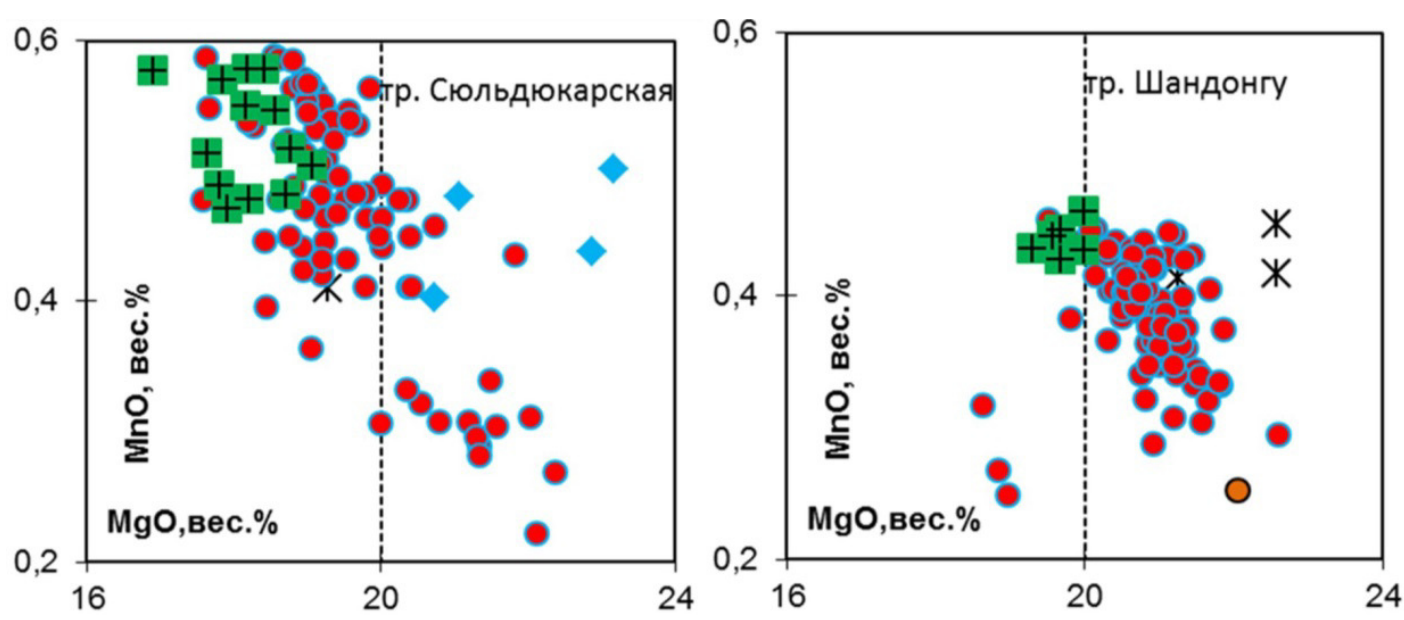

Puc. 2. Диаграммы MgO-MnO для составов пиропов из алмазоносного кимберлита трубки Сюльдюкарская (Якутия) и неалмазоносного кимберлита трубки Шандонг (Ангола). 


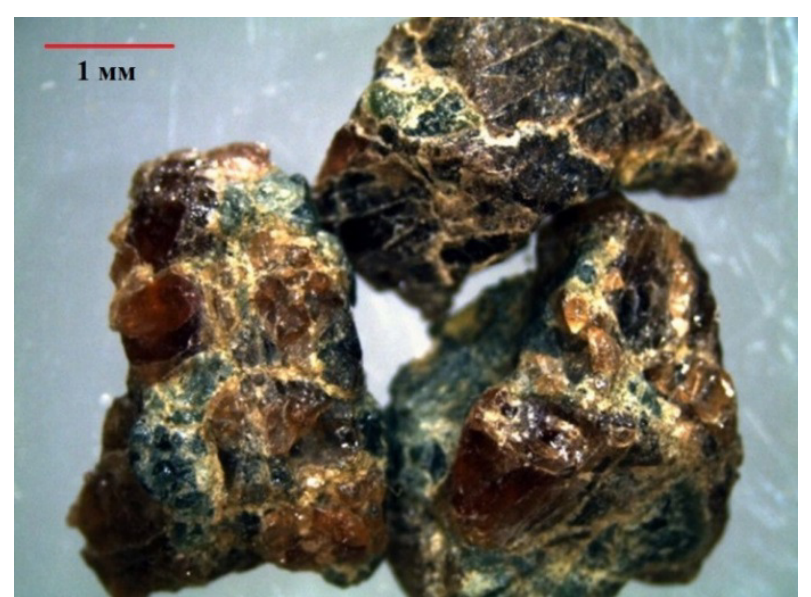

Puc. 3. Ксенолиты из кимберлитовой трубки Шандонгу.

Клинопироксены характеризуются достаточно высокими содержаниями окиси натрия (>3,0 мас. \%
$\mathrm{Na}_{2} \mathrm{O}$ ) и соответствуют типичным омфацитам с повышенной кальциевостью. Для них характерно высокое содержание титана (0,4 мас. \% $\left.\quad \mathrm{TiO}_{2}\right)$, небольшое количество хрома и полное отсутствие марганца (табл. 1).

Полученные данные позволяют сделать вывод о том, что ассоциации мантийных ксенолитов в кимберлитовой трубке Шандонгу представлены биминеральными эклогитами магнезиального типа, которые в большинстве случаев, вероятно, соответствуют безалмазным парагенезисам, что говорит о невысокой перспективности данной трубки. По трем опубликованным геотермометрам [3] были вычислены температуры совместной кристаллизации пиропа и клинопироксена в ксенолитах трубка Шандонгу при шести режимах давления (табл. 2). По полученным результатам видно, что температуры равновесия гранатов и клинопироксенов низки и не соответствуют области кристаллизации алмазов.

Таблица 1

Микрозондовый состав пиропа и клинопироксена

\begin{tabular}{|c|c|c|c|c|c|c|c|c|c|c|c|}
\hline Минерал & $\mathrm{Na}_{2} \mathrm{O}$ & $\mathrm{MgO}$ & $\mathrm{Al}_{2} \mathrm{O}_{3}$ & $\mathrm{SiO}_{2}$ & $\mathrm{CaO}$ & $\mathrm{TiO}_{2}$ & $\mathrm{Cr}_{2} \mathrm{O}_{3}$ & $\mathrm{MnO}$ & $\mathrm{FeO}$ & $\mathrm{Fe}_{2} \mathrm{O}_{3}$ & Сумма \\
\hline Пироп & 0,02 & 13,7 & 21,9 & 40,6 & 11,5 & 0,2 & 0,2 & 0,2 & 9,2 & 1,9 & 99,2 \\
\hline Пироксен & 3,2 & 12,8 & 6,5 & 53 & 19,6 & 0,4 & 0,1 & 0 & 0,6 & 2,3 & 98,4 \\
\hline
\end{tabular}

Таблица 2 магнезиальные альмандины. Отмечены близкие

РТ параметры кристаллизациии пиропа и клинопироксена

\begin{tabular}{|c|c|c|c|c|c|c|}
\hline $\mathrm{T}^{0} \mathrm{C} / \mathrm{P}$ (ГПа) & 10 & 20 & 30 & 40 & 50 & 60 \\
\hline Эллис, Грин & 632 & 656 & 680 & 704 & 728 & 752 \\
\hline Крох & 591 & 616 & 641 & 666 & 691 & 716 \\
\hline Берман & 442 & 469 & 493 & 514 & 533 & 550 \\
\hline
\end{tabular}

\section{Обсуждение результатов}

Составы пиропов трубки Сюльдюкарская отличаются более высокими содержаниями окиси марганца, в среднем на уровне значений 0,5 мас. \%, а содержания окиси магния - на уровне 19 мас. \% и их пироповый минал следовательно значительно ниже. Перекристаллизация ультраосновного состава магмы происходила с добавлением слоев более железистых эклогитов. Этот процесс происходил на больших глубинах и при больших давлениях, которые соответствовали температурам и давлениям для кристаллизации алмазов. Из данных статистических расчетов получается, что кристаллизация пиропов трубки Сюльдюкарская происходила при более высоких температурах, чем пиропов трубки Шандонгу.

Среди гранатов трубки Сюльдюкарска установлены пиропы ультраосновного парагенезиса и пиропальмандины эклогитового парагенезиса, а также содержания пиропов различных парагенетических ассоциаций ультраосновного парагенезиса между кимберлитами обоих тел этой трубки, за исключением зерен алмазной ассоциации дунитгарцбургитового парагенезиса, которые не обнаружены в низко алмазоносных кимберлитах западного тела. В восточном теле их доля составляет 4,0 \%. Пироп-альмандины эклогитового парагенезиса единичны.

Несмотря на близкие соотношения гранатов соответствующих парагенезисов, тела заметно различаются соотношениями кластерных групп, рассчитанных по Дж. Доусон и В. Стефенс [4]. Обращает внимание высокий процент $(17,65 \%)$ магнезиальных альмандинов кластерной группы G5 и необычно высокая доля $(36,76 \%)$ пиропов группы G10 в выборке из кимберлитов западного тела.

Исследование распределения редкоземельных элементов (РЗЭ) в пиропах сравниваемых трубок показало, что содержание РЗЭ в составах пиропов трубки Сюльдюкарская и трубки Шандонгу и их распределение весьма различно с повышенной концентрацией легких РЗЭ в кимберлитах трубки Сльдюкарская и более высоким содержанием средних РЗЭ в кимберлитах Шандонгу (рис. 4, 5). Существенно различаются кимберлиты этих двух трубок по содержанию $\mathrm{Lu}, \mathrm{Yb}, \mathrm{Tm}, \mathrm{Er}$, что четко прослеживается на пузырьковых диаграммах (рис. 5). 


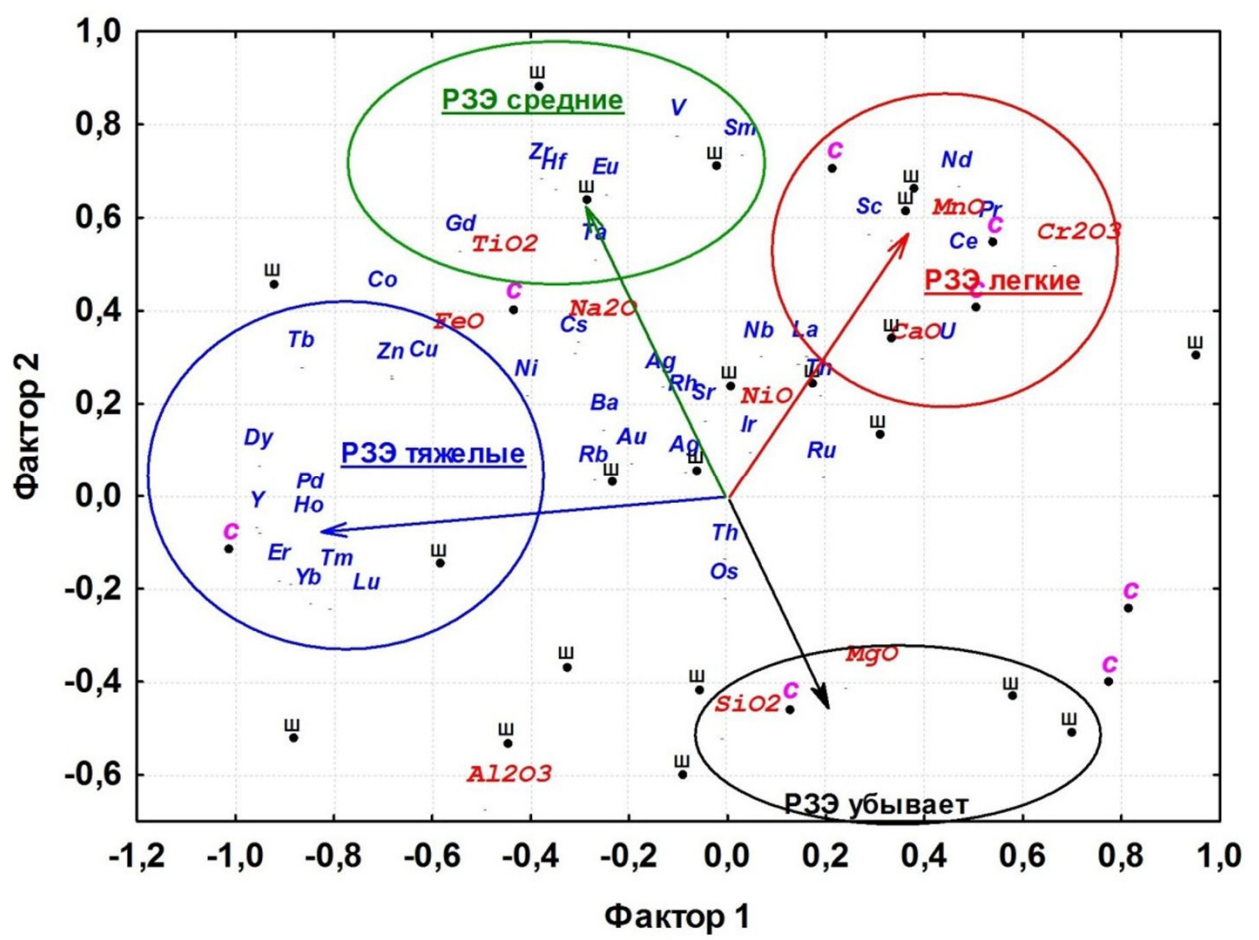

Puc. 4. Проекция на главные факторы содержаний основных и РЗЭ элементов из хромистых пиропов лерцолитовых парагенезисов из алмазоносного кимберлита трубка Сюльдюкарская (с) и неалмазоносноо кимберлита трубка Шандонгу (ш).

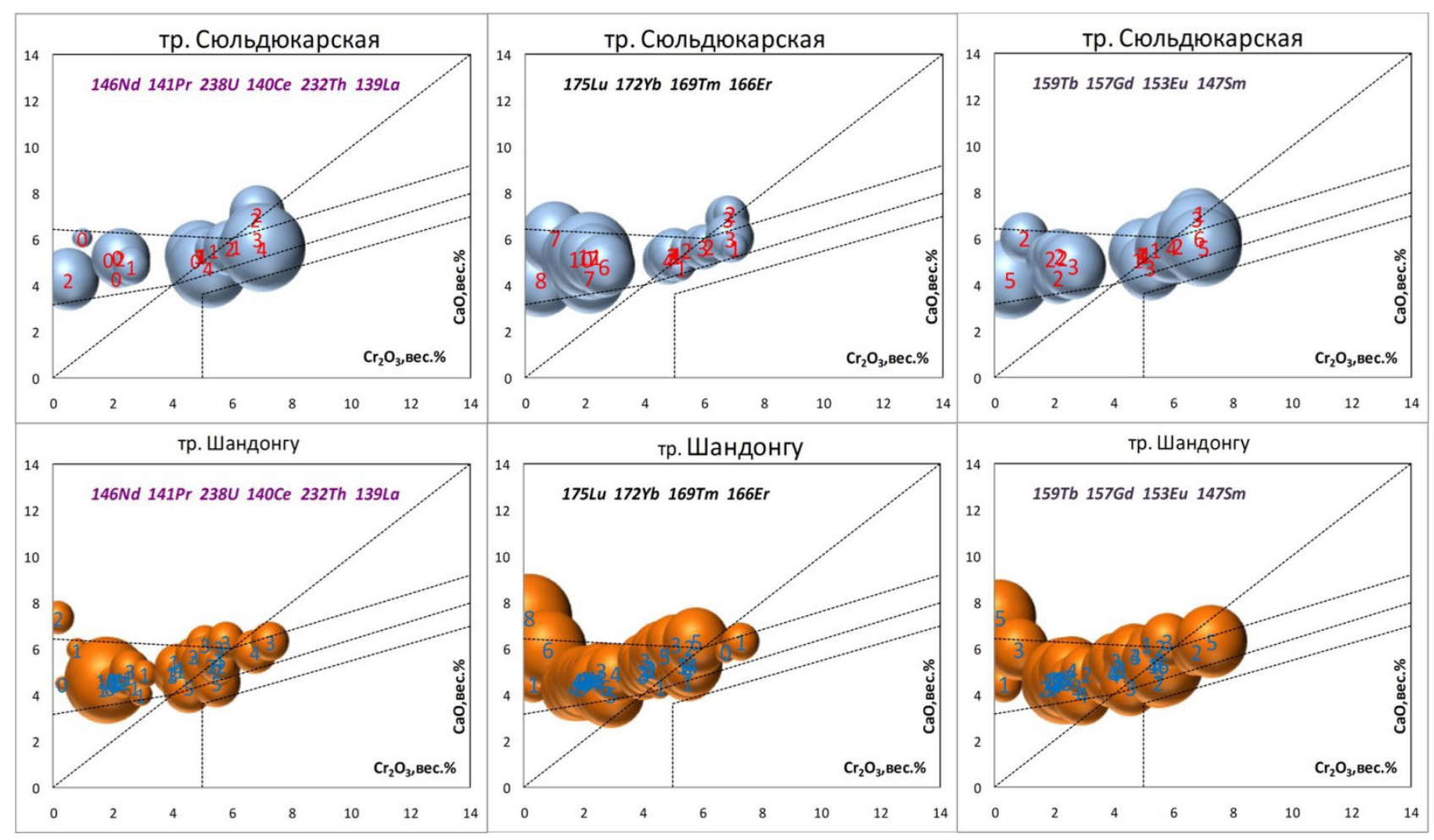

Puc. 5. Пузырьковые диаграммы концентраций Р3Э (в ppm, сверху - вниз: легких, тяжелых, средних РЗЭ) в пиропах на диаграмме Н. В. Соболева.

\section{Заключение}

Составы выборок пиропов из алмазоносных (трубка Селюдюкарская) и убого алмазоносных кимберлитов (трубка Шандонгу) с одинаковыми трендами распределения $\mathrm{CaO}-\mathrm{Cr}_{2} \mathrm{O}_{3}$ в области лерцо- литовых и алмазоносных дунит-гарцбургитовых парагенезисов, которые отражаются на основной диаграмме Н. В. Соболева, четко отличаются по содержанию окиси марганца и магния. Для алмазоносных кимберлитов характерны составы пиропов 
лерцолитовых парагенезисов с повышенными значениями окиси марганца более 0,4 мас. \% и пониженными значениями окиси магния менее 20 мас. $\%$.

Полная выборка зерен пиропа ультраосновных парагенезисов для высоко алмазоносных кимберлитовых тел проектируется на бинарную диаграмму $\mathrm{MgO}-\mathrm{MnO}$ в определенную кластерную область. Определенная методом подбора кластерная область на этой бинарной диаграмме характерна для большинства промышленных месторождений кимберлитов ЯАП [5]. Эту область составов можно характеризовать как температурную «мишень», в центр пересечения которой проектируются составы пиропов исключительно из продуктивных кимберлитов. Можно предположить, что составы пиропов с такими содержаниями магния и марганца происходят из мантийных пород благоприятных по РТ параметрам для кристаллизации в них алмазов.

Редкоземельные элементы (легкие, тяжелые и средние) неравномерно накапливаются в составах пиропов из алмазоносного кимберлита трубки Сюльдюкарская и неалмазоносного кимберлита трубки Шандонгу. Повышенная концентрация легких Р3Э в алмазоносной трубке Сюльдюкарская приходится на высокохромистые зерна пиропов до 4 ррм, а в низкохромистой области составов пиропов содержание РЗЭ менее 2 ррм. Для неалмазоносного кимберлита трубки Шандонгу концентрация легких РЗЭ в низкохромистых зернах пиропов более 10 ррм, в высокохромистых пиропах в два раза меньше.

Тяжелые Р3Э концентрируются в алмазоносных кимберлитах в большей степени в низкохромистых зернах пиропов эклогит-вебстеритовой ассоциации до 8 ррм, а в высокохромистой содержание легких РЗЭ в два раза меньше. Для пиропов из неалмазоносного кимберлита такое различие слабо выражено. Средние по весу РЗЭ равномерно концентрируются в зернах с разной градацией по хрому в алмазоносных и не алмазоносных кимберлитах. Пузырьковые диаграммы увеличивают информативность диаграммы Н. В. Соболева, при этом, на графике показывается дополнительная информация по различиям пиропов из алмазоносных и неалмазоносных кимберлитов.

\section{ЛИТЕРАТУРА}

1. Соболев, Н. В. О минералогических критериях алмазоносности кимберлитов / Н. В. Соболев // Геология и геофизика. -1971 . - №3. - С. 70-80

2. Геохимические особенности составов минералов новой кимберлитовой трубки Шандонгу (Ангола) / Т. М. Вунда [и др.] // Международная научно-практическая конференция. Актуальные проблемы геологии, прогноза, поисков и оценки месторождений твердых полезных ископаемых. - Судакские геологические чтения. - 2013. - IV (IX), - C. 14-16.

3. Ellis, D. J. An experimental study of the effect of Ca upon garnet-clinopyroxene Fe-Mg exchange equilibria / D. J. Ellis, D. H. Green // Contributions to Mineralogy and Petrology. 1979. -V. 71. - P. 13-22.

4. Dawson, J. B. Statistical classification of garnets from kimberlites and xenoliths / J. B. Dawson, W. E. Stephens // J. Geol. - 1975. - V. 83. - № 5. - P. 589-607.

5. Иванов, A. C. Новый критерий алмазоносности кимберлитов / А. С. Иванов // Труды ХІІ Всероссийской (с международным участием) Ферсмановской сессии. - Апатиты: КНЦ РАН. - 2015. - С. 268-270.

Scientific-research geological enterprise (NIGP) AK ALROSA (PAO), Mirny

тие АК «АЛРОСА» (ПАО), г. Мирный

Иванов Александр Сергеевич, кандидат геологоминералогических наук, ведущиий научный сотрудник E-mail:IvanovAS@alrosa.ru

Тел.: +7 (41136) 45718

Спечиус Здислав Витольдович, доктор геологоминералогических наук, главный научный сотрудник E-mail:Spetsiuszv@alrosa.ru

Тел.: +7 (41136) 45771

Толстов Александр Васильевич, доктор геологоминералогических наук, директор

E-mail:TolstovAV@alrosa.ru

Тел.: +7 (41136) 45718

ФГБУН Институт геологии и минералогии им. В. С. Соболева СО РАН, Новосибирск

Ащепков Игорь Викторович, кандидат геологоминералогических наук, старший научный сотрудник

E-mail: igor.ashchepkov@igm.nsc.ru

Тел.: +7 (383) 3332600
Ivanov A. S., Candidate of Geological and Mineralogical

Sciences, senior researcher, leading researcher

E-mail:IvanovAS@alrosa.ru

Tel.: +7 (41136) 45718

Spetsius Z. V., doctor of Geological and Mineralogical Sciences, chief researcher

E-mail: Spetsiuszv@alrosa.ru

Tel.: +7 (41136) 45771

Tolstov A. V., doctor of Geological and Mineralogical Sciences, director

E-mail: TolstovAV@alrosa.ru

Tel.: +7 (41136) 45718

S. Sobolev Institute of Geology and Mineralogy, Siberian Branch of RAS, Novosibirsk

Ashchepkov I. V., Candidate of Geological and Mineralogical

Sciences, senior researcher

E-mail: igor.ashchepkov@igm.nsc.ru

Tel.: +7 (383) 3332600 